\title{
STRESS ANALYSIS OF TWO DIFFERENT ATTACHMENTS FOR A TWO IMPLANT RETAINED MANDIBULAR OVERDENTURE
}

\author{
Amr A Rady* and Nouran Abdel Nabi*
}

\begin{abstract}
Background: Implant overdenture retained by two implants installed in the interforaminal area of the completely edentulous mandible has become the standard of care for completely edentulous patients. Various attachments have been used to retain a mandibular implant retained over denture, the ball attachment has been the most commonly used un-splinted attachment to retain a mandibular overdenture owing to its low cost and simplicity. A newly introduced attachment made from polyetherketoneketone (PEKK) which have reported to have high chemical and mechanical resistance to wear and high tensile, fatigue and flexural strengths. The aim of this in vitro study is to analyze the distribution of stresses around the two installed implants in the inter-foraminal area of a completely edentulous mandible using strain gauges utilizing an implant retained overdenture with two different types of attachments one with a nylon cap and the other with a PEKK cap.
\end{abstract}

Materials and Methods: A clear heat cured acrylic completely edentulous mandibular model has been used in this in vitro study to fabricate a lower conventional acrylic denture following conventional steps. In the canine region bilaterally two dummy implants were installed and attached to the model using self-cure acrylic resin. The acrylic resin was prepared around each implant into a box shape with a thickness of $1 \mathrm{~mm}$ into four surfaces; buccal, lingual, mesial and distal. Strain gauges of length $5 \mathrm{~mm}$, resistance of $120.4 \pm 0.4 \Omega$ and a gauge factor of $2.09 \pm 1 \%$, were attached to each surface. The same lower acrylic denture was used for pickup of the two attachments; the ball and CMLOC attachment. The implant retained overdenture retained by the each attachments was subjected to unilateral and bilateral vertical static load of $100 \mathrm{~N}$ using a universal testing machine. The wires of the strain gauges were connected to the strain meter to record the micro-strain using a special software, 10 readings were recorded for each attachment.

Results: when the implant retained overdenture have been subjected to unilateral loading, the loading side have recorded a higher statistically significant mean micro-strain than the unloaded side retained by both attachments, The overdenture retained with ball attachment have shown a significant increase in micro-strain on the loaded side than that with the CM LOC attachment, while for the unloaded side the overdenture retained with CMLOC attachment induced more micro strain than the ball attachment. While during bilateral loading, a statistically significant higher mean

* Lecturer of Removable Prosthodontics, Faculty of Oral and Dental Medicine, Cairo University 
micro strain was recorded in the left implant than the right implant, and the CM $1 \mathrm{OC}$ have shown a higher statistically significant mean micro strain than the ball attachment for the left implant , while the ball attachment have shown a statistically significant increase in micro strain for the right implant.

Conclusion: The newly introduced attachment the CM LOC tends to show a better performance with regards to the micro-strains induced around the implants and also regarding improving the stability of the denture, On the other hand the ball attachments despite having induced more microstrain around the implants, it could have a higher retention than the CM LOC attachment. Further studies comparing the retention of the new attachment CM LOC and the ball attachment has to be carried out to confirm the conclusion of the present study.

\section{INTRODUCTION}

Implant supported overdenture has become the standard of care for completely edentulous patients ${ }^{1}$. The Mc Gill consensus reported that an overdenture retained by two implants installed in the edentulous mandible is the minimal standard treatment option for the completely edentulous mandible. An over denture retained by two implants have improved patient satisfaction ${ }^{2-4}$ resulting in a more retentive and stable prosthesis, in addition to improvement in speech and esthetics, ${ }^{2,5}$ ease of cleaning and maintaining good oral hygiene ${ }^{6}$ has been considered to be an important advantage.

There are several types of attachment that can be used to retain an implant over denture, they are mainly classified into splinted attachments such as bar attachments or un-splinted attachments such as ball or locator attachment ${ }^{7}$. The un-splinted attachments have been more commonly used than the splinted attachment owing to the smaller space requirements within the prosthesis, ease of cleaning, more economical, and lower sensitivity to techniques ${ }^{8,9}$.

Ball and socket attachment has been the most popular un-splinted attachment to retain a mandibular overdenture, because its simplicity and cost effectiveness ${ }^{10}$. A newly introduced attachment made from polyetherketoneketone (PEKK) which is a member of the polyaryletherketones (PAEKs). Polyaryletherketones have the advantage of high chemical and mechanical resistance to wear and high tensile, fatigue and flexural strengths ${ }^{11}$. According to the manufacturer Cendres and Metaux, Polyetherketoneketone has $80 \%$ higher compressive strengths than other PAEK materials.

Masticatory functional load are normally transferred through the implants to the periimplant bone ${ }^{12}$.Excessive stresses transmitted to the underlying bone can result in bone resorption consequently resulting in implant failure ${ }^{13}$. The distribution of stresses around an implant would depend upon many factors such as; implant design and diameter ${ }^{14}$, abutment length ${ }^{15}$, angulation ${ }^{12}$, and its relation with the implant platform ${ }^{16}$. Various methods have been used to analyze the transmission of stresses to the underlying bone among them are; photo elastic, strain gauge and finite element analysis. Photo elastic analysis is of low cost, it's a simple methods, and it provides a qualitative analysis of the stresses present in the bone but doesn't allow an accurate measurement ${ }^{17}$. Strain gauges measures the deformation of a body by measuring its change in its electrical resistance, they provide quantitative data and can be used in vivo, and despite that the size and placement of the strain gauges are critical and could be a limiting factor ${ }^{17}$. The strain gauge technique will depend on recording the micro-strain through alteration of the electrical resistance. It will then convert the change in resistance to an electrical voltage which can be measured with great accuracy at the place where the strain gauge is placed ${ }^{18,19}$. 
Finite element analysis is a numerical method that would distinguish the materials by their physical properties, such as internal structure and modulus of elasticity ${ }^{20}$. Several studies have compared finite element analysis with strain gauges, the results were very controversial, Eser at al $2009^{21}$, reported a high degree of consistency between the two methods in analyzing bone deformities, both qualitatively and quantitatively, while Baiamonte T et al $1996^{22}$ and Palamara JE et al $\mathbf{2 0 0 2}^{23}$ found a good correlation between the two methods, on the other hand Akca et al $2002^{24}$ concluded that both methods identified the deformation induced, but the quantification of this deformation differed using both methods.

The aim of this in vitro study is to record the induced micro-strain around the two installed implants in the inter-foraminal area of a completely edentulous mandible using strain gauges utilizing an implant retained overdenture with two different types of attachments one with a nylon cap and the other with a PEKK cap.

\section{MATERIALS AND METHODS}

\section{Model fabrication and implant installation}

A mandibular cast simulating a clinical condition of a lower completely edentulous patient was duplicated into an acrylic resin model ${ }^{*}$ using a silicon mold ${ }^{* *}$. On the acrylic resin model, a trial denture base was fabricated using self-cured acrylic resin ${ }^{* * *}$. The trial denture base was checked for proper adaption and stability. A full set up of teeth was carried out on the lower trial denture, following all the clinical guidelines of complete denture teeth setup. The trial denture base was then waxed up, and then ready for flasking, packing and curing.
After de-flasking of the cured lower denture it was then finished and polished.

The lower denture was then checked for proper seating on the acrylic model. After ensuring proper seating the lower denture was duplicated into a clear acrylic stent, that will be used as a guide for implant installation. The clear acrylic stent was then modified to have a tunnel preparation from the right to the left canine area, keeping the labial surface of the stent intact. Drilling was carried out in the right canine area and left canine area using the clear acrylic stent. Two dummy implants were installed in the right and left canine area using a milling machine to ensure parallism of the two implants. The dummy implants ${ }^{* * * *}$ were attached to the cast by placing a soft mix of self-cure acrylic resin in the drilled holes during installation of the implants.

\section{Preparation of the model for installation of the strain gauges}

Preparation of the acrylic resin around each of the installed implants was carried out using a fissure bur. The preparation was of a box shape with a thickness of $1 \mathrm{~mm}$ of acrylic resin around each of the two implants, having four prepared surfaces; Buccal (B), Lingual (L), Mesial (M), and Distal (D).The four prepared surfaces had to be flat and parallel to the long axis of the implant each prepared surface had to be smoothened using sand paper before installation of the strain gauges to avoid incremental strains.

The installed strain gauge $\mathrm{e}^{* * * *}$ were of length $5 \mathrm{~mm}$, resistance of $120.4 \pm 0.4 \Omega$ and a gauge factor of $2.09 \pm 1 \%$. The strain gauges were attached to the four prepared; Buccal, lingual, Mesial, and

\footnotetext{
* Clear heat cured acrylic resin, Acrostone, Egypt

** Replisil 22n, Germany

*** Cold cure Acrylic resin , Acrostone, Egypt

**** Osteoseal dental implants, California, USA

***** Kyowa strain gauges, KFG-3-120-c1-11L1M2R, Japan
} 
Distal using a Cyanoacrylate based adhesive* The adhesive was left untouched for 24 hours for complete curing. Each wire of the installed strain gauge was labelled according to the surface it was attached to. In the acrylic resin model special channels were made on the sides of the model to secure the wires of the strain gauge and cover them with acrylic resin, to prevent dislodgment during measurement and also to prevent any damage to the wires. In this in-vitro study no dummy gauge was used in this study as the strain gauges were temperature-compensated for plastics.

\section{Attachments pick up}

The two attachments used in this in vitro study was the; Ball ${ }^{* *}$ and CM LOC attachment ${ }^{* * *}$. The two ball attachment of gingival height $2 \mathrm{~mm}$ were first screwed to the two implants with a torque of $25 \mathrm{Ncm}$ (Fig.1), and then the metal housing with the nylon cap were placed on top of the ball attachments. The Lower acrylic resin denture was then modified to have two holes corresponding to each of the ball attachment with their metal housing. A rubber dam was cut and placed around each of the ball

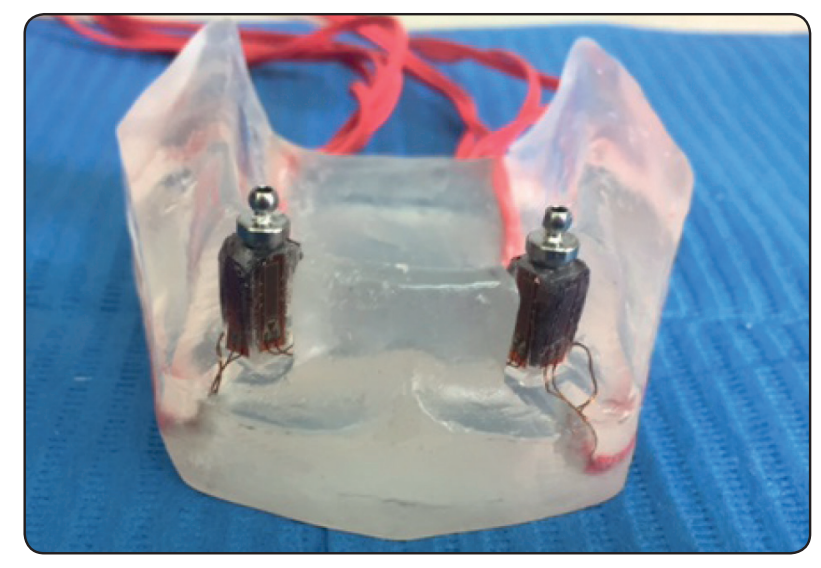

Fig. (1): Ball attachment screwed to the cast attachments to block the undercuts during pick up. The denture was ensured for complete seating by checking that there was no interferences between the metal housing and the acrylic resin of the drilled holes. A soft mix of self-cure acrylic resin was prepared and placed through the drilled holes of the properly seated denture. After complete setting of the self-cure acrylic resin, the denture was removed from the cast and all of the metal housing with the nylon cap were checked to be properly picked up in the fitting surface of the denture (Fig.2).

The denture with the ball attachment was then used to measure the strains around each implant. After all of the measurements were recorded, the metal housing with nylon cap was then removed from the fitting surface of the denture using a small fissure bur to remove the acrylic resin around the metal housing.

The ball attachment was unscrewed from the acrylic resin model, and the two CM LOC attachments of $2 \mathrm{~mm}$ gingival height were screwed to the two implants (Fig.3) with a torque of $25 \mathrm{Ncm}$. The Metal housing and the Pekkton cap (PEKK) was

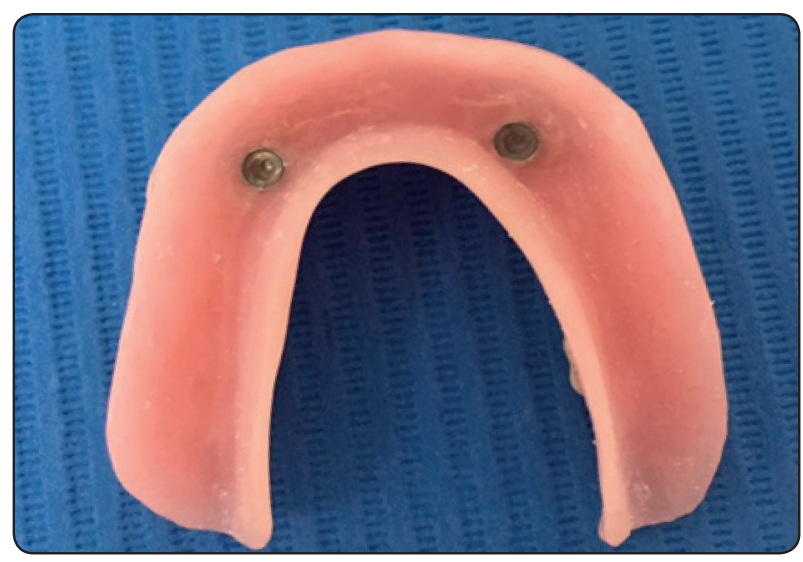

Fig (2): Nylon cap picked up in fitting surface of the denture

\footnotetext{
* CC-33 strain gauge cement, Kyowa electronic instruments co., Japan.

** Ball attachment, Zimmer Company, Biomet, Carlsbad, CA, USA

*** CM LOC attachment, Cendres and Metaux, Biel , Switzerland
} 


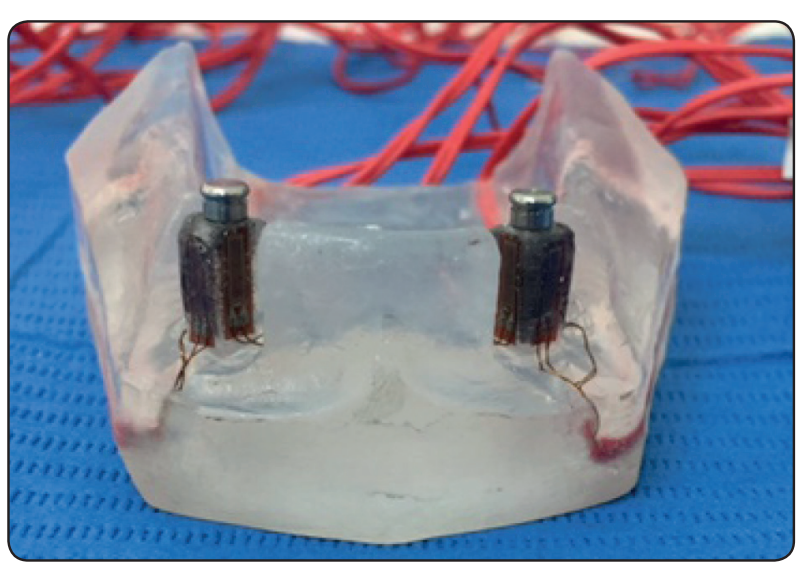

Fig (3); CM LOC attachment screwed to the acrylic cast

then placed over the CM LOC attachment, and the same denture that was used for the ball attachment was used for the CM LOC attachment. Pick up of the CM LOC attachments was carried out following the same steps for that of the ball attachments (Fig.4). The denture with the CM LOC attachment was then used to measure all of the strains around each implant.

\section{Loading and strain measurements}

In this in vitro study, the universal testing machine* was used to apply unilateral and bilateral vertical static load of $100 \mathrm{~N}$ for 15 seconds at a cross head speed of $0.5 \mathrm{~mm} /$ minute to simulate implant retained occlusal loads ${ }^{25}$. A small notch was prepared in the central fossa of the first molar tooth on the right and left sides. This rounded notch was prepared using a round bur and was prepared to be the repeatable point of load application (Fig.5). An I-shaped load applicator was used for unilateral loading, the load applicator was resting in the prepared notch of the first molar on the left side which is considered to the loading side, while the right side was considered to be the non-loading side. While for bilateral loading a $\mathrm{T}$ shaped load applicator was used to be resting

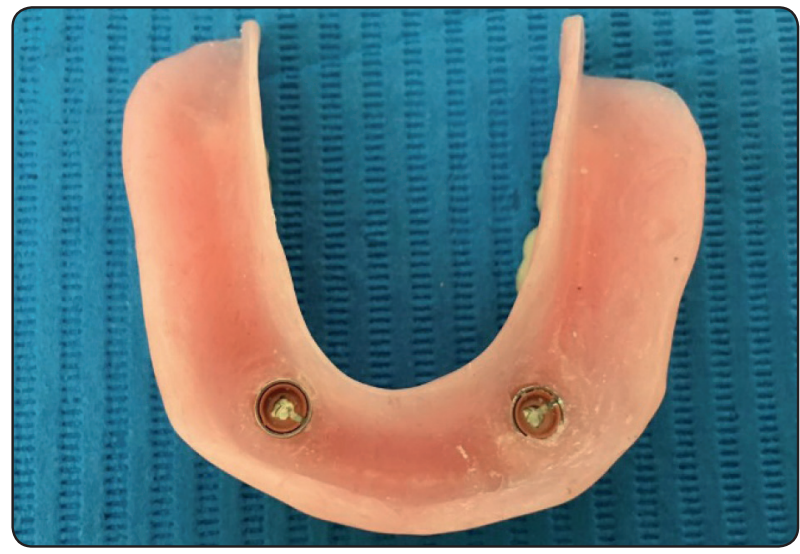

Fig (4): Pekkton cap picked up in the fitting surface of the denture

on both right and left first molar tooth to direct the loads to both sides of the arch (Fig.6).

The wires of the strain gauge of the four surfaces for each implant was connected to a multichannel strain meter ${ }^{* *}$ to record the micro-strain transmitted through the strain gauges for the four surfaces of each installed implants using a special software ${ }^{* * *}$. 10 readings were recorded for each of the two attachments, 5 minutes between each measurement was allowed for heat dissipation. All of the results were then tabulated and statistically analyzed.

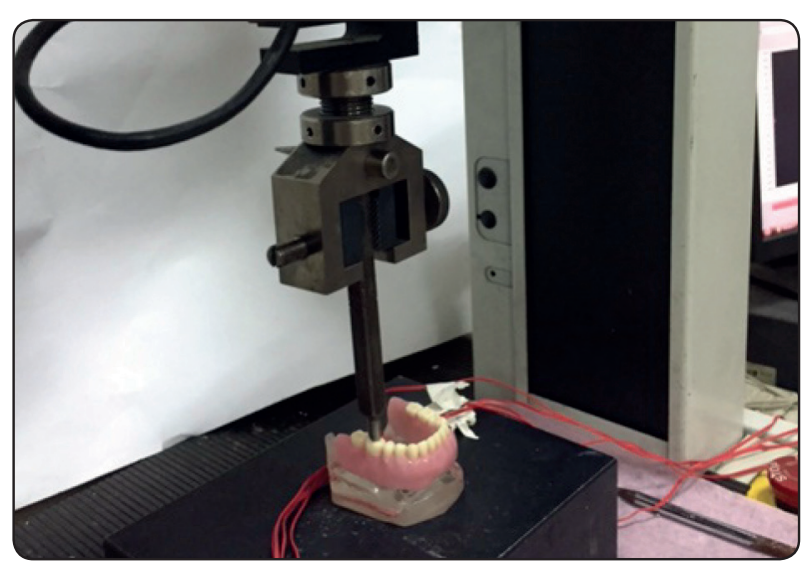

Fig (5): The universal machine directing unilateral vertical load.

\footnotetext{
* Lloyd LR5K instrument, Fareham, Hampshire, UK

** Model 8692, Tinsely precision instruments, Surrey, UK *** Kyowa Electronic Instruments Co.,Ltd, Japan
} 


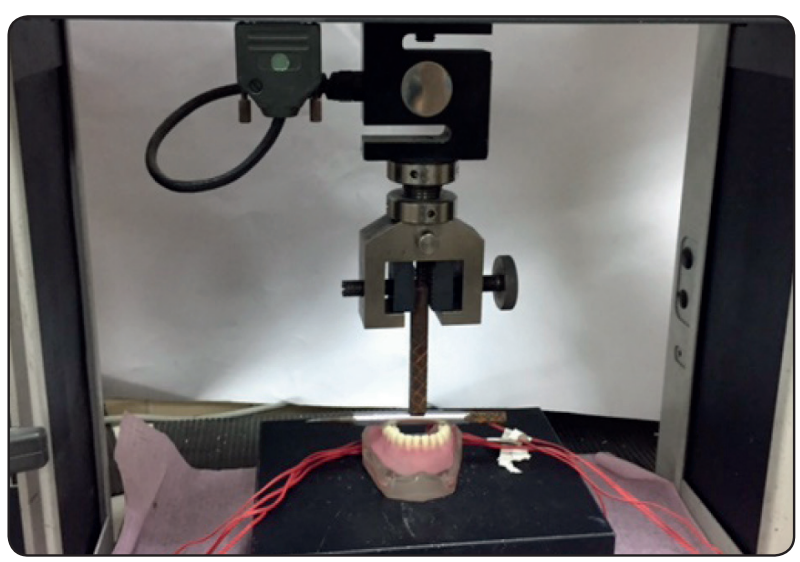

Fig (6): The universal testing machine directing bilateral loading

\section{RESULTS}

The mean and standard deviation values were calculated for each group. Data were explored for normality using Kolmogorov-Smirnov and Shapiro-Wilk tests and showed parametric (normal) distribution. Independent sample-t test was used to compare between independent samples. The significance level was set at $\mathrm{P} \leq 0.05$. Statistical analysis was performed with IBM ${ }^{\circledR} \quad$ SPSS $®$ Statistics Version 20 for Windows.

There was no statistically significant difference in the mean micro-strain recorded by the different surfaces; Buccal. Mesial, Distal, and Lingual for each implant, therefore all of the four surfaces were added up to represent a mean micro-strain recorded for each implant.

When unilateral vertical static load was applied in the central fossa of the left first molar which was considered to be the loaded side, while the right side was considered to be unloaded side. The mean micro-strains were recorded and compared for both attachments at the loaded and un loaded sides. For the two implant overdenture retained with the ball attachment it was found that there was a statistically significant differences in the mean micro-strains recorded between the loaded and the unloaded side $(\mathrm{p}<0.001)$, the loaded side recorded a higher mean micro-strain of $867.83 \pm 25.75$ when compared to the unloaded side which recorded $248.50 \pm 12.94$ mean micro-strain. For the CM LOC attachment, there was also a statistically significant difference in the mean micro-strains between the loaded and the unloaded side $(p<0.001)$, the loaded side have shown a greater significant mean micro-strain of $654.33 \pm 64.94$, while the unloaded side showed a mean micro-strain of $392.33 \pm 49.58$ (Table 1).

When comparing the mean micro-strains between the two types of attachments; the ball and the CM LOC at the loaded side a statistically significant difference in the mean micro-strain was detected. The overdenture retained with the ball attachment have shown a higher micro-strain of $867.83 \pm 25.75$ while the overdenture retained with the CM LOC attachment showed a lower mean micro-strain of $654.33 \pm 64.94$. While when comparing the mean micro-strains between the two attachments at the unloaded side, there was a statistically significant difference in the mean micro-strain, showing the CM LOC attachment to have a higher statistically significant mean micro-strain of $392.33 \pm 49.58$, while the ball attachment showed a lower mean micro-strain value of $248.50 \pm 12.94$ (Table 1) \& (Fig 7).

TABLE (1): The mean, standard deviation (SD) values of micro strain of unilateral loading of both groups.

\begin{tabular}{|c|c|c|c|c|c|}
\hline \multirow{3}{*}{ Variables } & \multicolumn{5}{|c|}{ Unilateral loading } \\
\cline { 2 - 5 } & \multicolumn{2}{|c|}{ Loaded side } & \multicolumn{2}{c|}{ Unloaded side } & \multirow{2}{*}{ P-value } \\
\cline { 2 - 5 } & Mean & SD & Mean & SD & \\
\hline Ball attachment & 867.83 & 25.75 & 248.50 & 12.94 & $<0.001 *$ \\
\hline CM attachment & 654.33 & 64.94 & 392.33 & 49.58 & $<0.001 *$ \\
\hline P-value & \multicolumn{3}{|c|}{$<0.001 *$} & \multicolumn{3}{c|}{$<0.001 *$} & \\
\hline
\end{tabular}

Means with different small letters in the same column indicate statistically significance difference, means with different capital letters in the same row indicate statistically significance difference. *; significant $(p<0.05)$ ns; non-significant ( $p>0.05)$ 


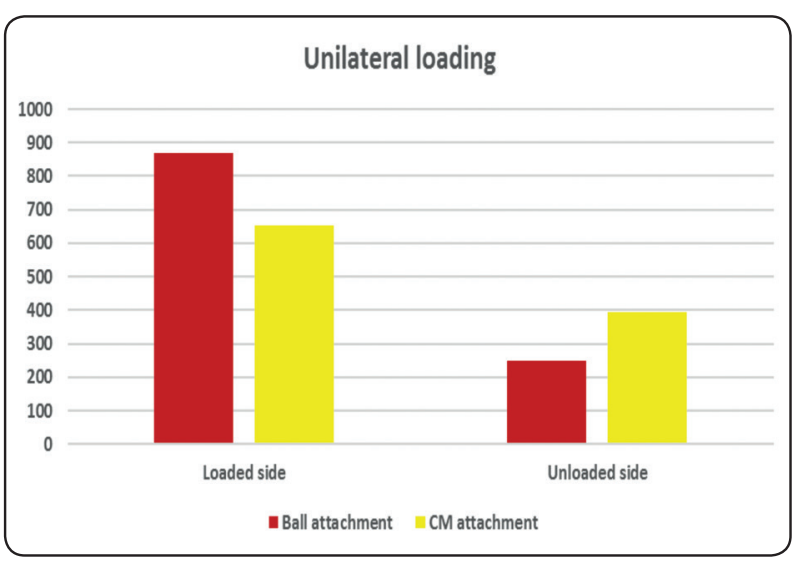

Fig (7): Bar chart showing the mean micro strain of unilateral loading for the loaded and unloaded side for the ball and the CM LOC attachment.

When bilateral vertical static load was applied on the left and right first molars, the mean microstrains for the left and right implants were recorded for the two types of attachments. There was a statistically significant difference in mean microstrains between the left and right implants for both the overdenture retained with the ball and the CM LOC attachment, with a higher mean micro strain recorded for the left implant for both attachment. For the ball attachment the left implant recorded a mean micro-strain of $612.50 \pm 76.15$ while the right implant recorded a mean micro-strain of 367.17 \pm 20.54. While the CM LOC attachment the left implant recorded a mean micro strain of $697.00 \pm$ 29.08 while the right implant the strain recorded was $78.17 \pm 12.49$ ( Table 2).

When the mean micro-strain recorded was compared between the left and the right implant during bilateral static loading for the two types of attachments, it was found that the overdenture retained with the CM Loc attachment had shown a statistically significant higher mean micro-stain when compared with the ball attachment at the left implant, the CM LOC recorded a mean micro- strain of $697.00 \pm 29.08$, while the mean micro-strain recorded by the ball was $612.50 \pm 76.15$. There was also a statistically significant difference between the mean micro-strains recorded using the ball and CM LOC attachment for the right implant, the ball attachment recorded the highest mean micro-strain of $367.17 \pm 20.54$, while that for the CM LOC the mean micro-strain was $78.17 \pm 12.49$ ( Table 3) $\&$ Fig (8).

TABLE (2): The mean, standard deviation (SD) values of micro strain of bilateral loading of both groups.

\begin{tabular}{|c|c|c|c|c|c|}
\hline \multirow{3}{*}{ Variables } & \multicolumn{5}{|c|}{ Bilateral loading } \\
\hline & \multicolumn{2}{|c|}{ Left Implant } & \multicolumn{2}{|c|}{ Right Implant } & \multirow{2}{*}{ P-value } \\
\hline & Mean & SD & Mean & SD & \\
\hline Ball attachment & 612.50 & 76.15 & 367.17 & 20.54 & $<0.001^{*}$ \\
\hline $\begin{array}{l}\text { CM LOC } \\
\text { attachment }\end{array}$ & 697.00 & 29.08 & 78.17 & 12.49 & $<0.001 *$ \\
\hline $\mathrm{P}$-value & \multicolumn{2}{|c|}{$<0.001 *$} & \multicolumn{2}{|c|}{$<0.001 *$} & \\
\hline
\end{tabular}

Means with different small letters in the same column indicate statistically significance difference, means with different capital letters in the same row indicate statistically significance difference. *; significant $(p<0.05)$ ns; non-significant ( $p>0.05$ )

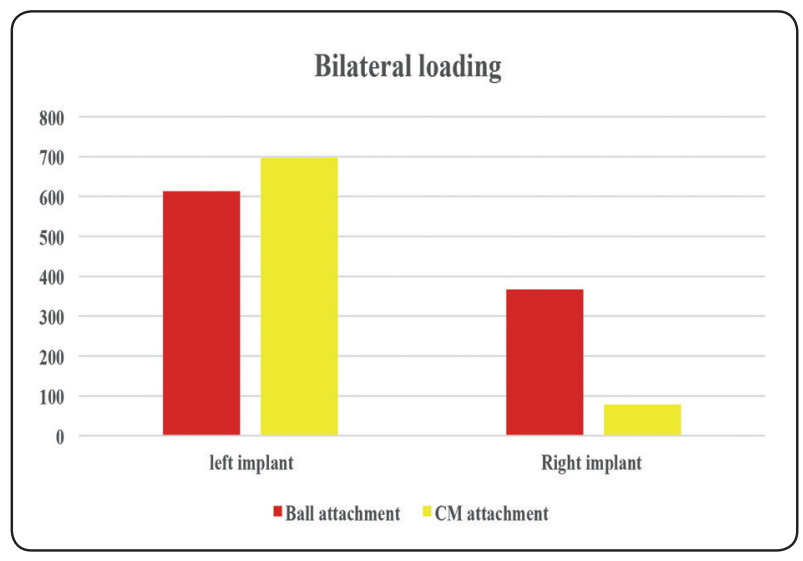

Fig (8): Bar chart representing means of micro strain of bilateral loading for the left and right implant for the ball and CM LOC attachment. 


\section{DISCUSSION}

An overdenture will be subjected to a variety of forces in different directions during occlusal loading. The application of functional loading will induce tension and strain to the bone/implant complex ${ }^{26-28}$, the amount of the occlusal load transmitted to the implant and the tension induced will depend upon the proximity of the point of load application ${ }^{29,30}$. A study have concluded that the implant closer to the load application will primary absorb most of the load ${ }^{31}$, this would explain the reason why the mean micro-strains during unilateral loading were statistically significantly higher on the loading side for both attachments; ball and CM loc than the mean micro-strain on the non-loading side.

When comparing the mean micro-strain between the ball and the CM LOC attachment on the loading side when subjected to unilateral loading, it was found that the overdenture with the ball attachment have recorded a statistically significant higher mean micro-strain than the overdenture retained with the CM LOC attachment, this would mainly be due to the ball and socket attachment acting as a fulcrum during loading of the mandibular overdenture ${ }^{32}$, this fulcrum is mainly present due to the absence of vertical resiliency as the ball and socket contact each other without intervening space. This comes in agreement with Assunaco et al 200933, who have concluded in a finite element analysis that high stress concentration were recorded with ball attachment on the loading side. On contrast the CM LOC attachment has a PEKK matrix design with a slot in the matrix, this slot will expand upon loading, thus resulting in more vertical resiliency that would allow movement of the prosthesis and so the CM LOC attachment will not act as a fulcrum during functional loading of mandibular overdenture.

On the contrary, when examining the unloaded side during unilateral loading, it was found that the mean micro-strain recorded by $\mathrm{CM}$ IOC attachment was statistically significantly higher than the mean micro-strain recorded by the ball attachment, this was because the fulcrum created by the ball attachment at the loading side led to disengagement of the denture from the ball at the non-loading side thus resulting in a decrease in the mean micro-strain. While the resiliency of the $\mathrm{CM}$ LOC attachment permitted vertical movement of the denture at the loading side, thus the denture was not able to dis-engage at the non-loading side due the frictional flanges of the CM LOC attachment and so resulting in higher micro-strains than that of the ball attachment.

In the present study when bilateral loading was applied on the right and left first molar areas, it was found that the left implant have recorded a higher statistically significant micro-strain than the right implant with the overdenture retained by the two types of attachment; ball and CM LOC attachment. Despite the fact that during bilateral loading, the loads are distributed to both sides but with an overdenture retained with two implants, when posterior loads are applied the overdenture will tend to rotate around a fulcrum line in the anterior area ${ }^{34,35}$, and due to this rotation the denture in this study was dis-engaged from the right side thus leading to a decrease in the mean micro-strain for the right implant.

When comparing the mean micro-strain induced during bilateral loading on the left implant for the overdenture retained by both attachments; the CM LOC attachment and the Ball attachment, it was found that CM LOC attachment have shown a higher statistically significant mean micro-strain than the ball attachment, that is due to the vertical resiliency of the CM LOC attachment that have resulted in less disengagement of the denture, when compared to ball attachment. During bilateral loading the overdenture have experienced a slight rotation around the fulcrum line, resulting in inducing more micro-strain to the left implant and dis-engaging from the right side with both attachments. when analyzing the micro-strain recorded at the right implant by both types of attachment it was found that the ball attachment have shown a higher 
statically significant mean micro-strain than the CM LOC attachment, that would indicate that the ball attachment have induced higher micro-strain during disengagement than the CM LOC which reveals that the ball would have a higher retentive capacity than the CM LOC attachment.. There tends to be a correlation between release period at which an attachment loses retention and the amount of stresses transferred to the abutments, the faster the attachment releases the less stress is placed on the abutments or implants ${ }^{36}$

In the present study all conditions were standardized where only the subject under study would be the only variable, the same denture was used for pickup for both attachments to decrease the variables and to standardize the denture base for both attachments that may affect the deformation that induces micro-strain, in addition to that the two types of attachments had the same gingival height of $2 \mathrm{~mm}$.

A limitation of this study is that there was no simulation to the resiliency of the muco-periostum posterior to the installed implants, the reason for not applying a soft resilient material was the difficulty in finding a material that will be dimensionally stable throughout the study. In the present study the acrylic resin mandibular test model was used to simulate the clinical situation, as this was done by many investigators ${ }^{25,37}$. This mandibular test model remained was constant throughout the experiment, in order to control the variables. Despite the fact that the physical properties of acrylic resins do not simulate the complex nature of living bone, for example mechanobiology of bone and osseointegration, so the results of this study will only be descriptive ${ }^{38,39}$.

It can be concluded from this invitro study that the newly introduced attachment the CM LOC tends to show a better performance with regards to the micro-strains induced around the implants and also regarding improving the stability of the denture, On the other hand the ball attachments despite having induced more micro-strain around the implants, it could have a higher retention than the $\mathrm{CM}$ LOC attachment. Further studies comparing the retention of the new attachment CM LOC and the ball attachment has to be carried out to confirm the conclusion of the present study.

As there is no one attachment that would fulfill the ideal requirements, because each clinical situation is unique, so careful selection of attachment is necessary to satisfy the patient's needs and expectations, as well as establishing a long term biologic and functional result.

\section{REFERENCES}

1- Fein, J.S. \& Carlsson, G.E. The McGill consensus statement on overdentures. In: Fein, J.S. \& Carlsson, G.E., eds. Implant Overdentures: The Standard of Care for Edentulous Patients, 2003; 155-157. Chicago: Quintessence Publishing Company.

2- MacEntee MI, Walton JN, Glick N: A clinical trial of patient satisfaction and prosthodontic needs with ball and bar attachments for implant-retained complete overdentures: three-year results. J Prosthet Dent 2005;93:28-37.

3- Meijer HJ, Raghoebar GM, Van't Hof MA: Comparison of implant-retained mandibular overdentures and conventional complete dentures: a 10-year prospective study of clinical aspects and patient satisfaction. Int J Oral Maxillofac Implants 2003;18:879-885.

4- Naert I, Alsaadi G, van Steenberghe D, et al: A 10-year randomized clinical trial on the influence of splinted and unsplinted oral implants retaining mandibular overdentures: peri-implant outcome. Int J Oral Maxillofac Implants 2004;19:695-702.

5- Naert I, Alsaadi G, Quirynen M: Prosthetic aspects and patient satisfaction with two-implant-retained mandibular overdentures: a 10-year randomized clinical study. Int J Prosthodont 2004;17:401-410.

6- Moberg LE, Kondell PA, Sagulin GB, et al: Branemark System and ITI Dental Implant System for treatment of mandibular edentulism. A comparative randomized study: 3-year follow-up. Clin Oral Implants Res 2001; 12:450-461. 
7- Sadowsky, S.J. Treatment consideration for maxillary implant overdentures: a systemic review. Journal of Prosthetic Dentistry 2007; 97: 340-348.

8- Trakas, T., Michalakis, K., Kang, K. \& Hirayama, H. Attachment systems for implant retained overdentures: a literature review. Implant Dentistry 2006; 15:24-34.

9- Alsabeeha, N.H.M., Payne, A.G.T. \& Swain, M.V. Attachment systems for mandibular two-implant overdentures: a review of in vitro investigations on retention and wear features. The International Journal of Prosthodontics 2009; 22: 429-440.

10- Fenlon MR, Palmer RM, Palmer P, et al: A prospective study of single stage surgery for implant supported overdentures. Clin Oral Implants Res 2002; 13:365-370.

11- Fuhrmann, G., Steiner, M., Freitag-Wolf, S., Kern, M. Resin bonding to three types of polyaryletherketones (PAEKs)-dur- ability and influence of surface conditioning. Dent. Mater.2014 30, 357-363.

12- Brosh T, Pilo R, Sudai D. The influence of abutment angulation on strains and stresses along the implant/ bone interface: comparison between two experimental techniques. J Prosthet Dent 1998;79:328-34.

13- Chun HJ, Shin HS, Han CH, Lee SH. Influence of implant abutment type on stress distribution in bone under various loading conditions using finite element analysis. Int J Oral Maxillofac Implants 2006;21:195-202.

14- Akça K, Cehreli MC. A photoelastic and strain-gauge analysis of interface force transmission of internal-cone implants. Int J Periodontics Restorative Dent 2008; 28:391-9.

15- Rubo JH, Souza EA. Finite element analysis of stress in bone adjacent to dental implants. J Oral Implantol 2008; $34: 248-55$.

16- Rossi F, Zavanelli AC, Zavanelli RA. Photoelastic Comparison of Single Tooth Implant-abutment Bone of Platform Switching vs Conventional Implant Designs. J Contemp Dent Pract 2011;12:124-30.

17- Karl M, Dickinson A, Holst S, Holst A. Biomechanical methods applied in dentistry: a comparative overview of photoelastic examinations, strain gauge measurements, finite element analysis and three-dimensional deformation analysis. Eur J Prosthodont Restor Dent 2009; 17:50-7.

18- Celland NL, Gilat A., McGumphy, EA, Brantley WA. A Photoelastic and strain gauge analysis of angled abutments for implant system. Int J Oral MaxilloFac Implants 1993 , 8; 541-8.

19- Kim WD, Jacobson Z, Nathanson D. Invitro stress analysis of dental implants supporting screw retained and cement retained prostheses. Implant Dent 1999; 8 (2):141:51.

20- Mellal A, Wiskott HW, Botsis J, Scherrer SS, Belser UC. Stimulating effect of implant loading on surrounding bone. Comparison of three numerical models and validation by in vivo data. Clin Oral Implants Res 2004;15:239-48.

21- Eser A, Akça K, Eckert S, Cehreli MC. Nonlinear finite element analysis versus ex vivo strain gauge measurements on immediately loaded implants. Int J Oral Maxillofac Implants 2009; 24:439-46.

22- Baiamonte T, Abbate MF, Pizzarello F, Lozada J, James $\mathrm{R}$. The experimental verification of the efficacy of finite element modeling to dental implant systems. J Oral Implantol 1996;22:104-10

23- Palamara JE, Palamara D, Messer HH. Strains in the marginal ridge during occlusal loading. Aust Dent J 2002;47:218-22.

24- Akça K, Cehreli MC, Iplikcioglu H. A comparison of three-dimensional finite element stress analysis with in vitro strain gauge measurements on dental implants. Int $\mathrm{J}$ Prosthodont 2002;15:115-21.

25- Porter J A., Petropoulos VC, Brunski JB. Comparison of load distribution for implant overdenture attachments. Int J Oral Maxillofac Implants 2002; 17: 651-62.

26- Bidez MW, Misch CE: Force transfer in implant dentistry: basic concepts and principls. J Oral Implantol. 1992,23:264-74.

27- Branemark PI,Zarb GA., Alberktsson T. Tissue -integrated prostheses. Osseointegration in clinical Dentistry. Chicago: Quintessence, 1987.p129

28- Van Oosterwyck H, Duyck J, Vander Sloten J., Van der Perre G, De Cooman M., Lievens S. et al. The influence of bone mechanical properties and implant fixation upon bone loading around oral implants. Clin Oral Implants Res 1998;9:407-418.

29- Assif D., Marshak B., Horowitz A. Analysis of load transfer and stress distribution by an implant supported fixed partial denture. J Prosthet Dent 1996, 75:285-91.

30- Skalak R. Biomechanical considerations in osseointegrated prostheses. J Prosthet Dent 1983,49:483-8. 
31- Sheppard IM: Denture base dislodgment during mastication, J. Prosthet. Dent. 1963; 13:462-468.

32- Elsyad MA, El-Waseef FA, Al-Mahdy YF, et al: A comparison of mandibular denture base deformation with different impression techniques for implant overdentures. Clin Oral Implants Res 2013; 24 Suppl A100:127-133.

33- Assuncao WG, Barao VA, Tabata LF, et al: Comparison between complete denture and implant-retained overdenture: effect of different mucosa thickness and resiliency on stress distribution. Gerodontology 2009; 26:273-281.

34- Chao, Y.L., Meijer, H.J., Van Oort, R.P., Versteegh, P.A. The incomprehensible success of the implant stabilised overden- ture in the edentulous mandible: a literature review on transfer of chewing forces to bone surrounding implants. Eur. J. Prosthodont. Restor. Dent.1995; 3, 255-261.

35- Mericske-Stern, R., Piotti, M., Sirtes, G. 3-D in vivo force measurements on mandibular implants supporting overden- tures. A comparative study. Clin. Oral Implant. Res. 1996; 7, 387-396.

36- Petropoulos VC, Smith W., Kousvelari Eleni. Comparison of retention and release periods for implant overdenture attachments. Int. J. Oral Maxillofac. Implants 1997; 12:176-85.

37- Gozde Celik, and Bulent Uludag . Photoelastic stress analysis of various retention mechanisms on 3-implant -retained mandibular overdentures. J. Prosthet. Dent. 2007;97:229-35.

38- Çehreli, M; Duyck, J; De Cooman, M; Puers, R; and Naert, I: Implant design and interface force transfer. Clin.Oral Impl.Res. 2004;15: 249.

39- Iplikcioglu H, Akca K, Cehreli MC, Sahin S. Comparison of non-linear finite element analysis with in vitro strain gauge measurements on a morse- taper implant. Int. J. Oral Maxillofac. Implants 2003;18:258-265. 